\title{
Complex interactions between components of individual prey specialization affect mechanisms of niche variation in a grasshopper-hunting wasp
}

\author{
Davide Santoro ${ }^{1}$, Carlo Polidori ${ }^{1 *}$, Josep D. Asís ${ }^{2}$ and José Tormos ${ }^{2}$ \\ ${ }^{1}$ Dipartimento di Biologia, Sezione di Zoologia e Citologia, Università degli Studi di Milano - Via Celoria, 26, Milan 20133, \\ Italy; and ${ }^{2}$ Unidad de Zoología, Facultad de Biología, Universidad de Salamanca-37071, Salamanca, Spain
}

\begin{abstract}
Summary
1. Individual foraging behaviour defines the use of resources by a given population and its variation in different ways such as, for example, unpredictable interactions between taxon-biased and size-biased selection. Here we investigated how the environmental availability of prey and individual specialization, for both prey taxa and prey size, shape niche variation across generations in the grasshopper-hunting digger wasp Stizus continuus.

2. The population of $S$. continuus expressed selective predation, females mainly hunting species encountered on large bushes; diet changed across generations, due more to size increase in potential prey than to changes in the orthopteran community.

3. Individual females of both generations weakly overlapped the size and taxa of prey, and the niche width of the second generation increased for both prey size and taxa.

4. The greater variance in prey size in the environment accounted for the enlarged prey size niche of the second generation, but the load-lifting constraints of the wasps maintained individual prey size specialization constant. In contrast, the enlarged prey taxon niche paralleled a smaller overlap of diets between wasps in the second generation.

5. Increased niche width in the $S$. continuus population was thus achieved in two ways. Regarding prey size, all individuals shifted towards the use of the full set of available resources (parallel release). For prey taxa, according to the classical niche variation hypothesis, individuals diverged to minimize resource use overlap and perhaps intraspecific competition. These two mechanisms were observed for the first time simultaneously in a single predator population.
\end{abstract}

Key-words: niche variation hypothesis, parallel release, predation, resource availability, solitary wasp

\section{Introduction}

Specialization of a population can be defined according to different conceptual frameworks (Ferry-Graham, Bolnick \& Wainwright 2002). For example, an 'ecological specialist' is a species that utilizes a narrow range of resources, while a 'functional specialist' is a species that is forced to use a narrow range of the available resources because it is 'mechanically' constrained to that subset (Ferry-Graham, Bolnick \& Wainwright 2002; Irschick, Dyer \& Sherry 2005). Because they are not ecologically equivalent, the same concepts can be applied to single individuals, which can show different degrees of intraspecific resource overlap. This individual specialization is widespread in the animal kingdom and can be invoked to explain the majority of the population niche

*Correspondence author.E-mail: carlo.polidori@unimi.it width, thus having important ecological, evolutionary and conservation implications (reviewed by Bolnick et al. 2003).

The realized niche is frequently narrower than the fundamental (potential) niche (the manifestation of species genotype in the environment) and reflects how extrinsic factors such as competition, predation or other ecological interactions affect the population and individual niche (Futuyma \& Moreno 1988). Regarding diet, the realized niche corresponds to the natural diet, e.g. the prey a predator actually eats in nature. An opportunistic population of a predator would hunt each prey species with a frequency not very different from its abundance in the environment (Polidori et al. 2007, 2009, 2010; Huseynov, Jackson \& Cross 2008); in contrast, an opportunistic individual in a predator population would have a prey spectrum reflecting that of the whole population (Bolnick et al. 2003). Both levels of analysis are important and should ideally be carried out at the same time 

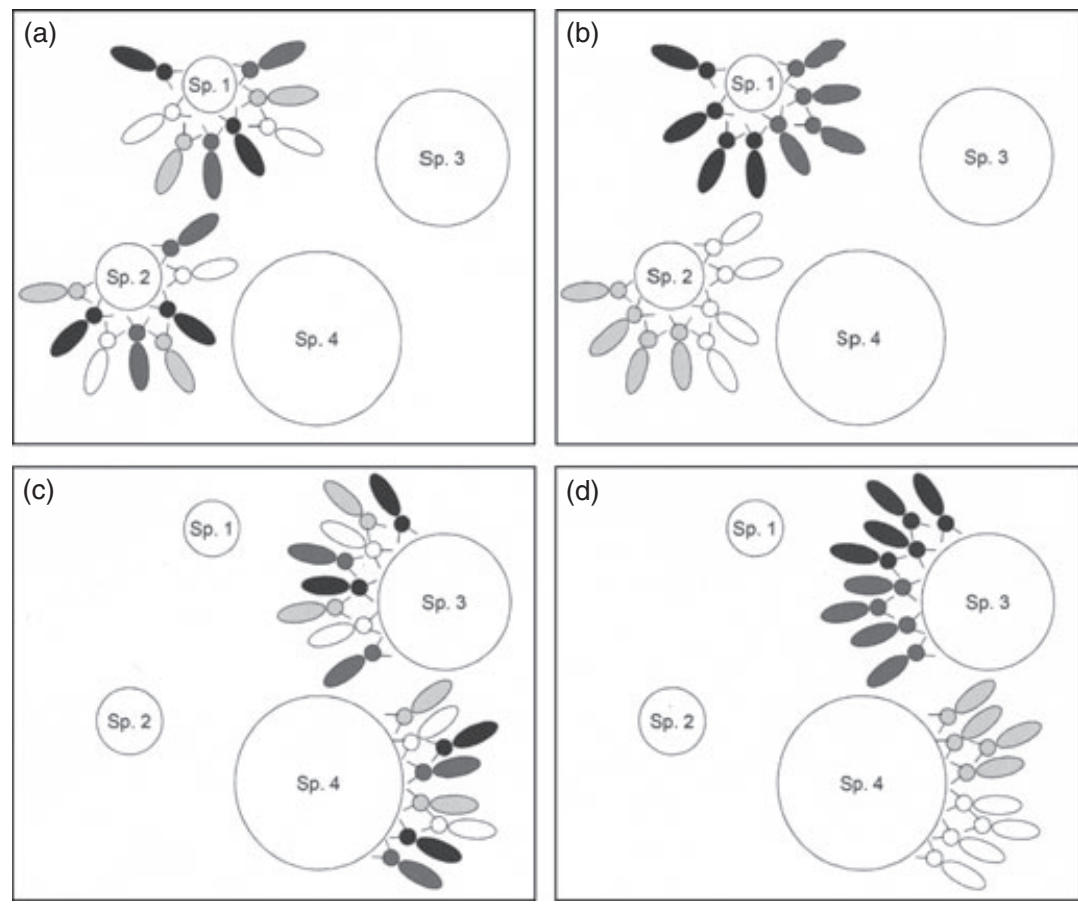

Fig. 1. Schematic representation of the possible relationships between taxonomic prey specialization of the population and that of its individuals. Four individuals of a population and four species of prey available in the environment, differing in abundance, are considered. Females collected four prey items each. In case (a), wasps hunt only the two rarer species (small circles), each female focuses equally on both of them; this reflects a high taxon-biased preference but null individual taxonomic specialization. In case (b), two wasps hunt one rare species and the other two the other rare species; this results in high taxon-biased preference and high individual taxonomic specialization. In case (c), wasps hunt only the two abundant species (large circles), each female focusing equally on each; this reflects a low taxon-biased preference and null individual taxonomic specialization. Finally, in case (d), two wasps hunt one abundant species and the other two the other abundant species; this reflects a low taxon-biased preference and high individual taxonomic specialization. Case (b) represents the maximum degree of taxonomic specialization, while case (c) represents the maximum degree of taxonomic generalism. Moving the females in a variety of ways on the four prey species leads to the other possible degrees of taxonomic specialization. The same models can also be applied to prey size classes instead of taxa.

for a given population, because the hypothesis that populations and individuals behave opportunistically is generally not supported by empirical evidence. Thus, opportunism or specialization may appear at population and/or individual level (see Fig. 1).

The same concept is also valid when considering prey size classes instead of prey taxa. Under size constraints, consumers efficiently exploiting one type of resource are inefficient using another type of resource (Bolnick et al. 2003). For example, larger individuals can detect, capture and consume both small and large prey items, whereas small predators are usually restricted to small prey (Barclay \& Brigham 1991; Polidori et al. 2005) and thus large individuals may be capable of using a broader range of prey species than smaller ones if different prey species fall in different prey size classes (e.g. Liao, Pierce \& Larscheid 2001); alternatively, larger predators might avoid smaller prey, weakening the relationship between predator size and niche breadth (e.g. Costa 2009). These patterns, in turn, would affect the arrangement of interaction strengths and consequently food web stability (Emmerson \& Raffaelli 2004).

Furthermore, the niches of individuals and populations vary with time. This niche variation may simply reflect the changes occurring in prey availability or may be linked to other additional factors. Increased niche width could, in principle, be achieved in two ways. First, all individuals might shift to use the full set of available resources (parallel release) (Bolnick et al. 2010). Alternatively, each individual might continue to use a narrow range of resources but diverge from its conspecific competitors to minimize resource use overlap and competition: increased population diet breadth is thus achieved by greater between-individual variation (Bolnick et al. 2007). Following the 'niche variation hypothesis' (NVH) (Van Valen 1965), populations with wider niches are more variable (e.g. morphologically or behaviourally) than populations with narrower niches. Populations may broaden their niche through this mechanism if interspecfic competition decreases and/or intraspecific competition increases (Bolnick 2001; Svanbäck \& Bolnick 2007; Bolnick et al. 2010). It is also possible, evidently, that increased individual niche width does not correspond to a variation in population niche, because expansion may be offset by decreased between-individual variation (individual release) (Bolnick et al. 2010). Again, the same model of niche variation may not necessarily apply to both prey taxa and prey size for a given predator population (e.g. Araújo \& Gonzaga 2007), so that considering simultaneously both diet axes (and their relationship) is extremely important. 
This theoretical framework gives rise to some fundamental questions: (1) How does individual-level specialization for prey taxa and size interact and shape population-level selectivity? (2) Do unpredictable interactions between prey taxa and size lead to different mechanisms of niche variation in time? (3) Do changes in environmental availability of prey taxa and the environmental distribution of prey size account for such mechanisms? To try to answer to these questions, a grasshopper-hunting predatory wasp was used as a model species.

\section{Materials and methods}

\section{STUDY ORGANISM AND STUDY AREA}

Stizus continuus (Klug) (Hymenoptera: Apoidea: Crabronidae) (Fig. 2) is a Mediterranean digger wasp; females dig multicellular nests and hunt orthopterans to feed their offspring (Polidori et al. 2009). Stizus continuus, like most digger wasps (O'Neill 2001), is a central-place forager, nesting in dense aggregations and hunting for a single insect order, which allow many prey to be collected easily from wasps' nests. Moreover, females of Apoidea generally collect resources at relatively short distances from their nesting sites (Greenleaf et al. 2007), thus sampling potential prey from the environment around nests is reasonably easy. These characteristics make S. continuus a good model to investigate patterns of resource specialization.

Data were collected in the area of 'Mallada Llarga' at 'Dehesa del Saler', in the 'Parque Natural de l'Albufera' (Valencia, Spain). Small, thick bushes of Salicornia ramosissima (J. Woods) and Sarcocornia fruticosa (L.), large patches of Juncus maritimus Lam. and Phragmites australis Cav. as well as groves of Pinus maritimus (Morgan) cover most of the study area (see also Polidori et al. 2009). A large nest aggregation of $S$. continuus (about $200 \mathrm{~m}^{2}$ in total extension, see also Polidori et al. 2008) was chosen for the study. At this location, S. continuus is bivoltine, with generations partially overlapping (Polidori et al. 2008).

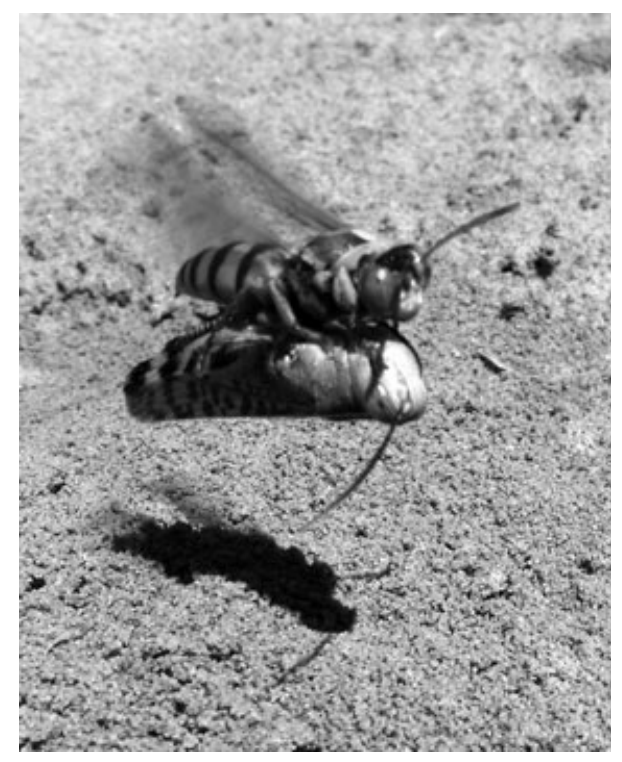

Fig. 2. A marked female of $S$. continuus carrying its paralysed prey (Heteracris littoralis adult male).
The field work was conducted during the summer of 2007, between 8 July and 4 September, spanning the nesting activity of both generations (Polidori et al. 2008). In 2007, a series of rain storms clearly separated the activity of the two generations, interrupting the activity of the first generation (active until 4 August) and shifting the emergence of the individuals of the second generation (active after 12 August).

\section{PREY COLLECTION AND SURVEY OF WASP ACTIVITY}

Eighty-eight females of $S$. continuus (42 from the first generation and 46 from the second generation) were captured with an entomological net, marked with nontoxic, soft felt-tip pens (Unipaint marker; Mitsubishi Pencil Co., Tokyo, Japan), weighed with an Ohaus Navigator field balance (to the nearest $0.002 \mathrm{~g}$ ) and then released.

To obtain prey, marked females carrying grasshoppers were recaptured and, once deprived of the prey, released. No more than one prey item from the same individual was collected per hour. The prey were weighed immediately after collection, placed in closed test tubes and frozen. Subsequently, they were identified following the keys of Clemente, Garcia \& Presa (1987) and by comparisons with a previous collection made in the same area (Polidori et al. 2009). A total of 479 prey items were taken from 77 wasps, $1-20$ ( $6 \pm 5$ on average) per wasp.

To evaluate a possible effect of intraspecific competition on individual specialization, we needed a measure of wasp density. To achieve this, over 37 days during the study period, we made 5-min counts of the number of active nests (i.e. in course of provisioning) in four patches $\left(1 \mathrm{~m}^{2}\right)$ randomly fixed in the wasps' aggregation and then obtained a simple measure of wasp activity density ( $A D=$ mean number of active nests per patch). On the whole, the patches were randomly surveyed 529 times.

\section{SAMPLING OF ORTHOPTERA IN THE ENVIRONMENT}

Sampling of the orthopterans in the environment was performed over 42 days. One ten-minute, nonlinear transect was carried out each hour from 9.00 to 17.00 (solar hours) in a radius of about $500 \mathrm{~m}$ around the aggregation, intersecting ecologically different patches (e.g. open areas, Sarcorcornia bushes), based on previous collections in the same area (Polidori et al. 2009 and unpublished data).

Sweep net sampling and visual searches were performed to capture the grasshoppers, according to common protocols (Evans, Roger \& Opferman 1983; Badih et al. 1997). Considering the habitat type and biological traits of the target taxa (e.g. low mobility), we believe abundance provides a reasonable estimation of availability (Johnson 1980).

Each sampled grasshopper was associated with one of the following microhabitats: (i) ground, leaf litter and short grass $-<20 \mathrm{~cm}$ in height, (ii) tall grass, shrubs, trees. In total, 705 grasshoppers from 174 transects were collected.

The orthopterans were weighed and identified as described earlier. The vast majority $(96 \%)$ of the orthopterans could be identified at generic level, and in the analysis, we refer to this taxonomic level. However, because no more than one species per genus was found (see Results and Table S2), we concluded that the probability of having collected individuals of more than one species per genus was very low (see also Polidori et al. 2009).

\section{DATA ANALYSIS}

To evaluate the role of prey size on wasp selectivity, we estimated the load-lifting capacity of the wasps. For each wasp, using the 
previously published regression of flight muscle mass on body mass for S. continuus (Polidori et al. 2009) and through the equation provided by Marden (1987), we estimated the maximum load that could theoretically be carried in flight. We then compared these values with the actual prey weights (Coelho \& Ladage 1999). Because wasp weight and maximum lift were normally distributed (Jarque-Bera test: $0.7<\mathrm{JB}<1.4,0.5<P<0.8$ ) but variances were not homogeneous, the Aspin-Welch test was used instead of the Student's $t$-test to compare wasp weights and theoretical maximum loads between generations.

Because intraspecific competition could affect interindividual prey overlap (see Introduction), a rough measure of orthopteran density $(O D)$ was calculated as the ratio between the number of collected individuals and the number of transects, and this was divided by wasp $A D(O D / A D)$. This roughly estimated how much prey were available per wasp and hence the level of competition. $A D$ was calculated for 37 days and $O D$ for 26 days; both measures were obtained simultaneously for 22 days. We then regressed $O D / A D$ against dates to evaluate its temporal variation. To verify whether $A D$ and $O D$ varied between generations, the Mann-Whitney $U$-test was used.

\section{MEASURING GENERATION-LEVEL SELECTIVITY BY ENVIRONMENTAL AVAILABILITY}

A contingency table was built to test for prey taxon selectivity, comparing the observed number of individuals per genus stolen from the wasps with the expected ones, i.e. by multiplying, for each genus, the total number of prey by the proportion belonging to that genus of the total sampled in the environment (Polidori et al. 2009).

The relative selectivity of the two wasp generations for each prey genus was quantified using the standardized residual $(S R=$ (observed-expected)/expected ${ }^{1 / 2}$ ). To test whether wasps hunt the common genera at disproportionate rates compared with others (i.e. they form search images while hunting), $S R$ for the genera was plotted against their frequencies in the environmental sample and a Pearson's correlation test was performed. The overlap between the generationlevel niche and the orthopteran community was estimated by measuring the sample similarity between the frequency distribution of genera used and that of genera in the environment (Czekanowsky's proportional similarity index, PS) (Hurlbert 1978; Feinsinger \& Spears 1981) (Table S1).

As comparing prey selectivity between generations can reflect either prey growing into size refuges, or wasps changing their prey taxon preferences without regard to size, we considered size-specific selectivity, i.e. by breaking down each of the three most abundant genera (the smaller sample size of the other ones prevented the split in size classes) into four size classes; we then compared prey and environmental sample frequencies for each size class with a contingency table, as described earlier. Size classes were as follows: 1-50, 51-100, 101-200 and > $200 \mathrm{mg}$. We calculated the generation-level total variance in weight distribution both for prey ( $T N W$, see below) and for environmental sample (Table S1). Comparisons of such variances were performed with the $F$-test. The relative effects of period of collection (generation), the type of sample (prey or environment), the genus and the interactions between these factors on the variance of orthopteran weight were tested by an ANOva. Mean weight was subtracted from each weight (mean-centring, see e.g. Aiken \& West (1991)) to achieve normality (Jarque-Bera test: JB $=5 \cdot 7, n=1086$, $P=0 \cdot 06$ ).

A contingency table was built for each generation to test for habitat preference in the different genera of the grasshoppers, comparing the observed frequencies in each habitat with the expected ones, with reference to general abundance in different habitats.

\section{MEASURING THE GENERATION-LEVEL NICHE WIDTH}

Niche width for prey taxa was measured with Levins' $D$ index (Levins 1968), which estimates how wide the niche is, taking into account the relative use of the different resources (Table S1).

To compare the niche width $(D)$ between generations, 10000 nonparametric bootstrap re-samplings were generated for each one, using the NicheWidth program (Araújo \& Gonzaga 2007). If the overlap between 2.5 and 97.5 percentiles ( $95 \%$ confidence limits around $D$ values) does not overlap, there is a significant difference between the niche widths of the two generations. $D$ was also calculated for the environmental sample to allow comparisons with niche width of wasps; in this case, $\mathrm{q}_{\mathrm{j}}$ is the proportion of $j$ th genus in the community.

Niche width for prey weight was measured as the total variance in weight distribution $(T N W)$ (Table $\mathrm{S} 1)$.

\section{MEASURING THE INDIVIDUAL-LEVEL NICHE WIDTH AND NICHE OVERLAP}

To analyse individual diets, 43 individuals with at least four prey were considered: this was the minimum value that guaranteed an absence of correlation between the number of prey items and the number of corresponding genera $(r=0 \cdot 16, n=43, P=0 \cdot 30)$.

The similarity between the diet of the individual $i$ and the diet of the generation (intraspecific overlap in prey taxa) was measured with the $P S$ index adapted to individual-level analysis $\left(P S_{i}\right.$, Bolnick et al. 2002) (Table S1). The mean value of $P S_{i}(I S)$ expresses the average individual specialization for a generation (Table $\mathrm{S} 1$ ). Individual niche width $\left(D_{i}\right)$ for prey taxa was calculated as for the generationlevel niche width $(D)$, but using the proportion of each resource category in the individual diets (Levins 1968).

To measure individual specialization for prey weight, we used Roughgarden's index (R's I) (Roughgarden 1974) for continuous data (Bolnick et al. 2002) (Table S1); this index is based on the within-individual component and the between-individual component of the total niche width $(T N W=W I C+B I C)$ (Table S1). A parametric correlation test (Pearson) was used to look for significant linear associations between the size of the wasps and the mean size of prey and between the size of the wasps and the coefficient of prey weight variation $(\mathrm{CV}=$ standard deviation/mean).

The indices of individual specialization $\left(P S_{i}\right.$ and $R$ 's $\left.I\right)$ were calculated with the IndSpec1 program (Bolnick et al. 2002). IndSpec1 uses a nonparametric Monte Carlo procedure to generate replicate null diet matrices drawn from the population distribution, from which $P$ values can be computed (Bolnick et al. 2002). Ten thousand replicates in Monte Carlo bootstrap simulations were performed. Nonparametric comparisons of $D_{i}$ and $I S$ of the two generations were tested with the Mann-Whitney $U$-test.

In the following text, mean values are reported \pm standard deviation.

\section{Results}

\section{PREY SPECTRUM AND ORTHOPTERAN COMMUNITY}

The orthopterans belonged to 16 genera, in six families (Table S2). Almost all the prey and the environmental spectra 
were composed by Acrididae ( $85 \%$ and $84 \%$, respectively) and Pyrgomorphidae (11\% and $12 \%$, respectively); the other families did not reach 2\%. Seven genera (Calliptamus, Acrotylus, Pyrgomorpha, Tropidopola, Sphingonotus, Anacridium and Heteracris) encompassed $>95 \%$ of the total number of individuals collected (Table S2), so that in the following analyses, we refer only to these seven genera. Most of the grasshoppers were in the nymph stage $(81 \%$, $n=1184)$, both with respect to prey $(82 \%, n=479)$ and those collected from the environment $(80 \%, n=705)$. The sex ratio was 1 : 1 (45\% for both males and females and $10 \%$ undetermined) for the grasshoppers in the environment, and 1.2 males to females in the case of prey, not differing from $1: 1\left(\chi^{2}=2 \cdot 06\right.$, d.f. $\left.=1, P=0 \cdot 15\right)$.

During the season, variations occurred in the orthopteran community. In July, the most abundant genus was Acrotylus; in August, Calliptamus became the most representative genus, Tropidopola grew in number and Heteracris appeared (Table S2). The available prey spectrum $(D)$ was wider in the second generation, when othopteran density $(O D)$ was higher (3.4 $\pm 1 \cdot 4, n=76$ vs. $5 \cdot 4 \pm 4 \cdot 6, n=88$ ) (Mann-Whitney $U=2369, P<0.001$ ) (Table 1). Each genus showed a statistically significant preference for one of the two habitats distinguished (Table S3). Pyrgomorpha was subject to a niche shift between July and August (Table S3).

\section{WASP ACTIVITY}

There was increased wasp activity in the aggregation during August: the $A D$ index of the first generation $(0 \cdot 9 \pm 1 \cdot 2$, $n=265)$ was significantly lower than that of the second generation $(2 \cdot 0 \pm 1 \cdot 6, n=264)$ (Mann-Whitney $U=2673$, $P<0.001)$. $O D / A D$ weakly decreased across the period $(r=-0 \cdot 44, n=22, P=0 \cdot 041)$, suggesting there was increasing intraspecific competition in the second generation.

\section{GENERATION-LEVEL SELECTIVITY: PREY TAXA}

The wasps appeared to be selective (Table S2). The two generations showed a different rank of preference towards the same prey taxa (Fig. 3). Whereas in the first generation Anacridium and Calliptamus were overhunted, in the second generation, Tropidopola was preferred as prey, followed by Anacridium and Pyrgomorpha, and Heteracris appeared among prey. Acrotylus and Sphingonotus were significantly ignored by both generations (Table S2, Fig. 3). Prey belonged mostly to genera found on bushes and tall grasses (Table S3). Wasps did not seem to form search image while hunting, as shown by the absence of correlation between $S R$ and frequencies in the environment (Pearson test: first generation: $r=-0 \cdot 25, n=10, P=0 \cdot 48$; second generation: $r=-0 \cdot 26, n=11, P=0 \cdot 44$ ) (the genera with null frequency in the environment were excluded). Wasps of the first generation used a narrower proportion of environmental resources than those of the second generation (Table 1).

The niche of the second generation was significantly wider than that of the first: there was no overlap between the confi- dence intervals around the $D$ measures of the first (1.244$2 \cdot 377)$ and second (3.205-4.572) generations (Table 1).

\section{GENERATION-LEVEL SELECTIVITY: PREY SIZE}

The weight of females of the two generations did not differ (first generation: $176 \pm 45 \mathrm{mg}$; second generation: $176 \pm$ $42 \mathrm{mg})(t=0 \cdot 01$, d.f. $=86, P=0.99)$. Accordingly, the maximum theoretical load was similar in the two generations (Table S4) (first generation: $178 \pm 25 \mathrm{mg}$, second generation: $185 \pm 24 \mathrm{mg}, t=-0 \cdot 94$, d.f. $=86, P=0 \cdot 17$ ).

Total variance in orthopteran weight in the environment was much higher in the second generation than in the first (Table 1), and it was significantly broader than prey size variance $(T N W)$ for the second generation only $\left(F_{407,201}=4 \cdot 49\right.$, $P<0.001)$. There was an increase in prey size variances across generations (Table 1). Parallel, the first generation of wasps used a narrower range of prey sizes than the second one (Table 1). The analysis of variance (Goodness-of-fit: $R^{2}=0 \cdot 38$; ANOVA: $F=32 \cdot 4$, d.f. model $=20$, d.f. error $=1065$ $P<0.0001$ ) showed that the weight of orthopterans (only the seven most abundant genera were used) depended on the period (grasshoppers from the second generation weighed more than those from the first one: $F=40 \cdot 22$, SS $=10 \cdot 57$, $P<0.0001)$, from the genus $(F=3 \cdot 2, \quad \mathrm{SS}=5 \cdot 0$, $P=0.004)$ and from two interactions (type of sample $\times$ genus: $F=7.84$, SS $=12.37, P<0.0001$; generation $\times$ genus: $F=22 \cdot 28, \quad \mathrm{SS}=29 \cdot 29, \quad P<0.0001) . \quad$ In particular, Pyrgomorpha $(F=9 \cdot 8, P=0.002)$, Acrotylus $(F=10 \cdot 3, P=0.001)$ and Tropidopola $(F=21 \cdot 6, P<$ $0 \cdot 0001)$ were all smaller in the environment than among prey (all $P<0.01)$, while Calliptamus $(F=41, P<0.0001)$, Acrotylus $(F=11.7, P=0.001)$ and Sphingonotus $(F=$ $5.9, P=0.015)$ grew significantly between July and August (all $P<0.01)$ (Table S4). All the other interactions had no effect on weight.

For the genus Calliptamus, strongly preferred by the first generation overall, positive selectivity concerned only the lower size classes, with the larger individuals being underrepresented in the diet (Fig. 3, Table S5). In the second generation, Calliptamus was, on the whole, less hunted than its environmental abundance, and this trend was confirmed for all the size classes (Fig. 3, Table S5). Overall, this suggests that only smaller individuals of this prey genus were conspicuously used. With respect to the genus Tropidopola, wasps preferred medium and large individuals, while smaller ones were selected slightly less frequently (Fig. 3, Table S5). Smaller individuals of Pyrgomorpha were avoided by the first generation but strongly selected by the second generation, regardless of size (Fig. 3, Table S5).

\section{INDIVIDUAL SPECIALIZATION (INTRASPECIFIC OVERLAP): PREY TAXA}

Evidence of significant segregation of the prey spectrum among individuals was found in both generations (Fig. 4, Table 1), and the mean intraspecific overlap in prey taxa $(I S)$ 


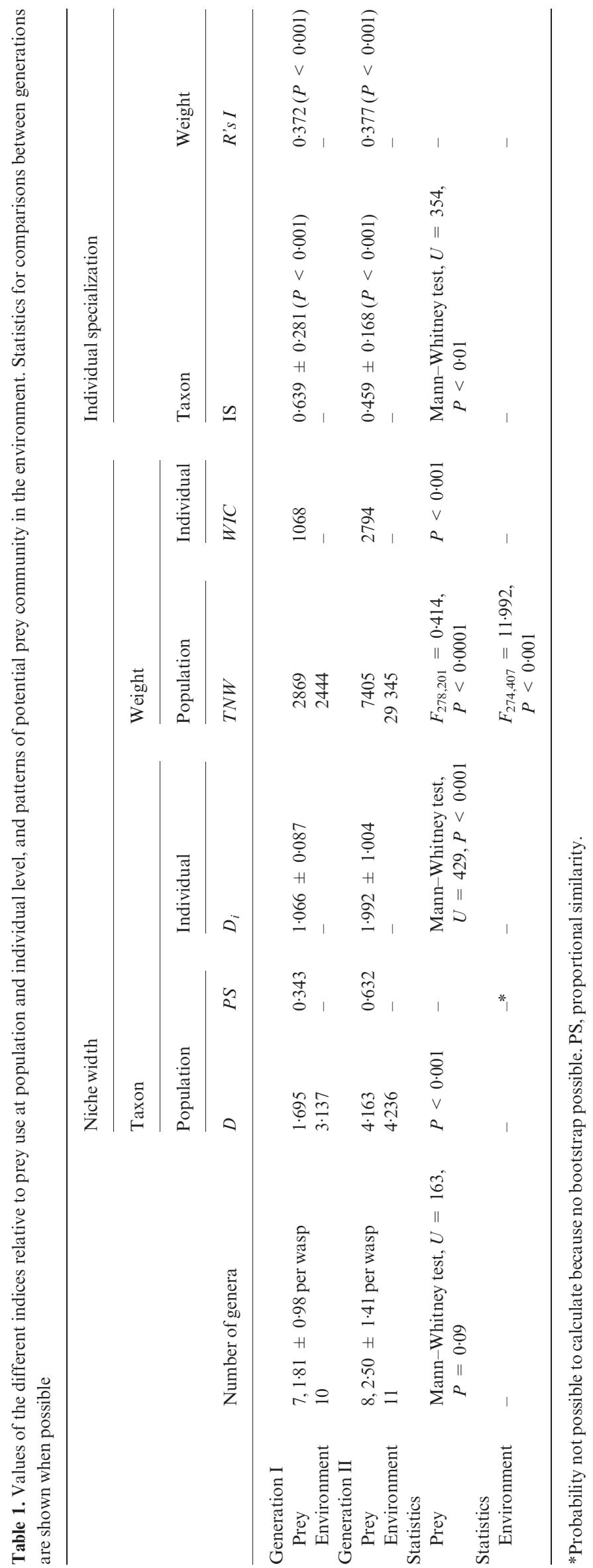

(C) 2011 The Authors. Journal of Animal Ecology (C 2011 British Ecological Society, Journal of Animal Ecology, 80, 1123-1133 


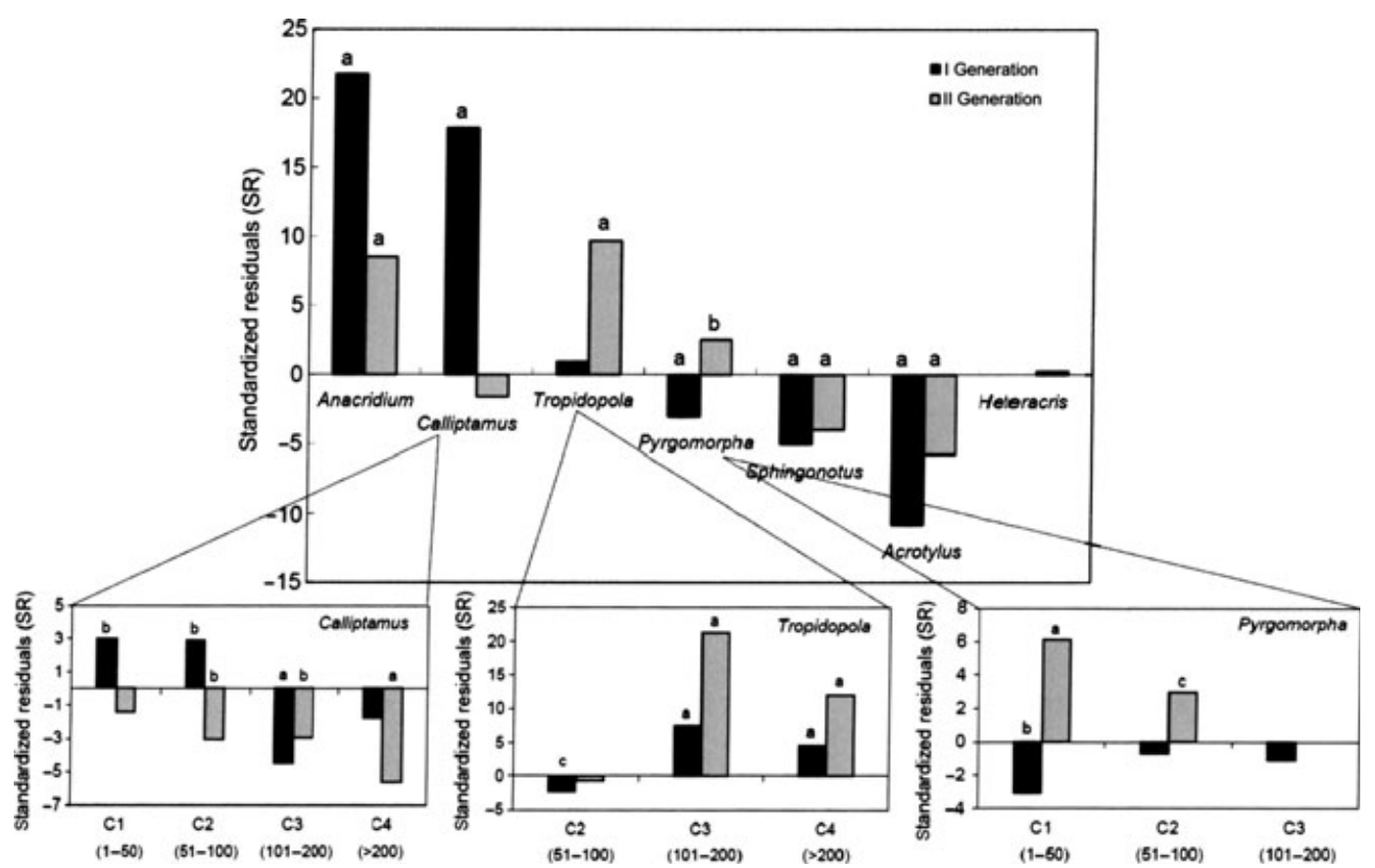

Fig. 3. Diet preference (considering only the seven most abundant genera) of the wasps from the two generations. Here preference is measured as standardized residuals $(S R)$. For the three most abundant genera, selectivity was further calculated by dividing samples into size classes (see text for further details). Ranks below the bars indicate the range of $\mathrm{mg}$ for the size classes; (a): $P<0.001$, (b): $P<0.01$, (c): $P<0.05$, no letter: $P>0.05$.

Fig. 4. Individual diet spectrum for the 43 wasps with at least four prey items.

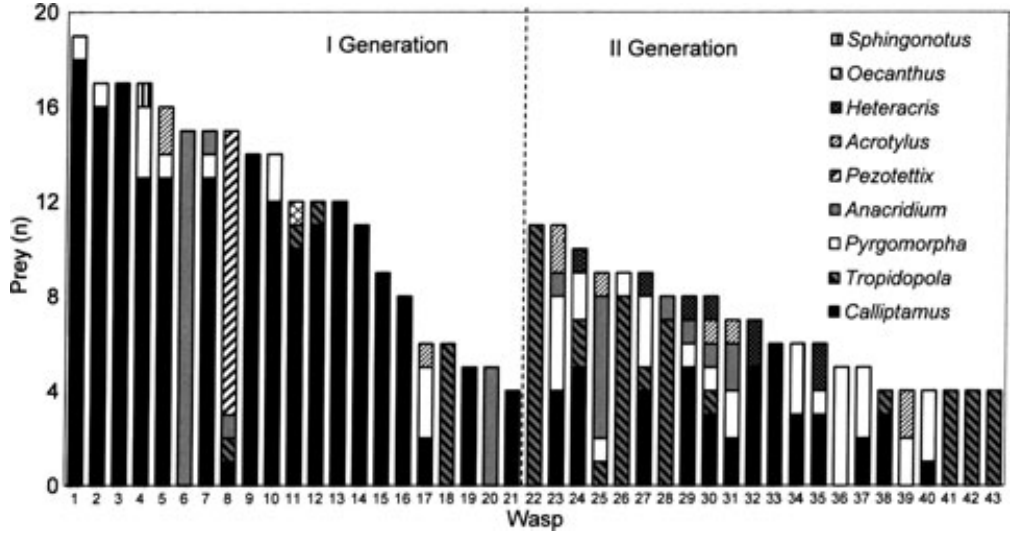

was weaker in the second generation (Table 1). The increase in generation niche width $(D)$ was accompanied by a proportionally lower increase in individual niche width $\left(D_{i}\right)$ (Table 1).

\section{INDIVIDUAL SPECIALIZATION: PREY SIZE}

Highly significant individual specialization in prey size ( $R$ 's $I)$ was found in both generations (Table 1). The broader niche width of the second generation $(T N W)$ corresponded to a proportional increase in the niche width of single individuals (WIC). Thus, the two R's I values were very similar (Table 1).

There was a positive correlation between the weight of the wasps and the mean weight of their prey only in the second generation (first generation: $r=0 \cdot 37, n=20, P=0 \cdot 113$; second generation: $r=0.68, n=22, P<0 \cdot 001$ ) (Fig. 5). Individual variance in prey weight $(C V)$ did not increase with wasp weight in the first $(r=0 \cdot 11, n=21, P=0.63)$ or in the second generation $(r=-0.083, n=22, P=0 \cdot 71)$. Moreover, in the first generation, we found no correlations between lower or upper quartile of prey weight and wasp weight (I quartile: $r=0 \cdot 35, n=21, P=0 \cdot 13$; III quartile: $r=0 \cdot 39, n=21, P=0 \cdot 08)$, while for the second generation, we found a weak increase in the lower quartile ( $r=0 \cdot 45, n=22, P=0 \cdot 04)$ and a strong increase in the upper quartile $(r=0.89, n=22, P<0.0001)$ with wasp weight. This suggests that in August, larger wasps strongly preferred larger prey but still consumed an important number of smaller prey. 


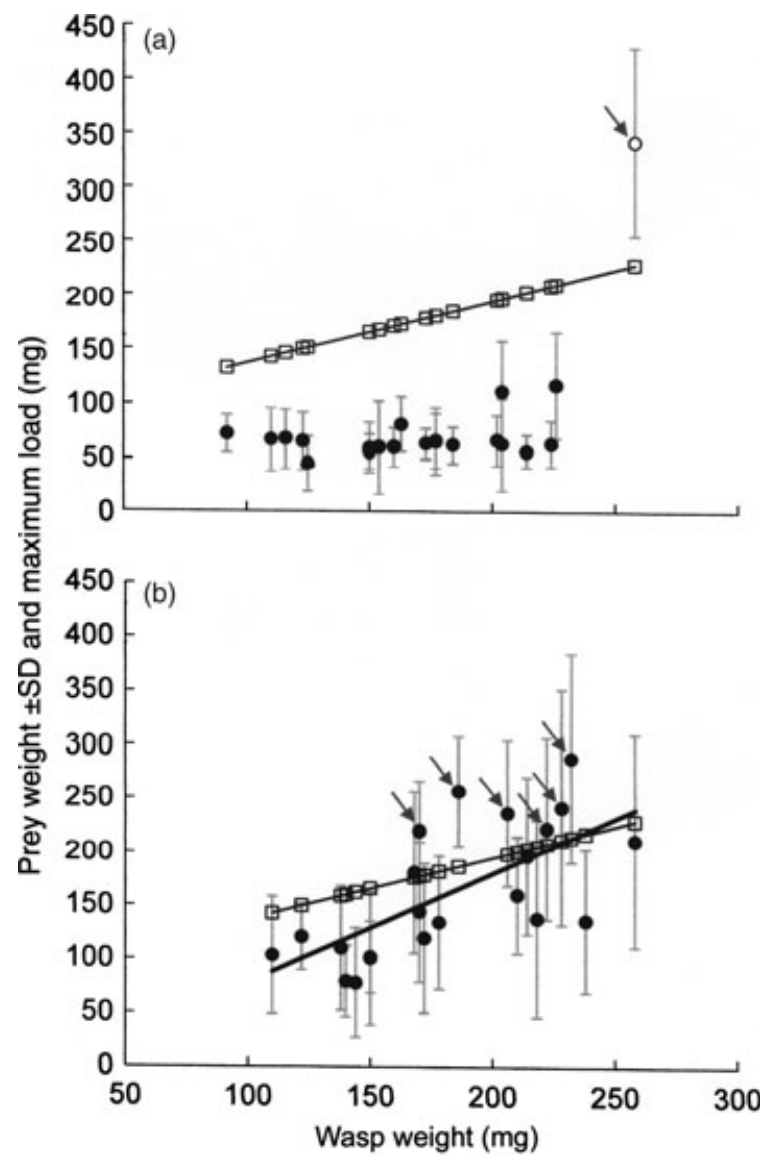

Fig. 5. Correlation between wasp weight and mean prey weight (filled circles and bold line), and correlation between wasp weight and theoretical maximum load that can be lifted (empty squares and thin lines), in the two generations. Only the 43 wasps with at least four prey items were used. Grey arrows indicate the wasps which carried prey, on average, larger than the maximum theoretically transportable in flight. The white circle in (a) refers to the outlier of the first generation, not used in the correlation test.

In the first generation, prey taken to the nest weighed much less than the maximum theoretical load transportable in flight (Table S4, Fig. 5); in contrast, in the second generation, prey taken to the nest approached the maximum theoretical load, and almost coincided with the mean weight of grasshoppers available in the environment. Several wasps even hunted for prey that exceeded their lifting capacity in flight (Fig. 5), so they were probably forced to carry them by walking after gliding from tall objects. In particular, Calliptamus prey became much larger in the second generation and exceeded, on average, the lifting capacity of wasps (Table S4).

\section{Discussion}

Recovering the questions addressed in the Introduction, we first clearly found that individual specialization was strong in the two generations, both in prey size ( $R$ 's $I)$ and in prey taxa (IS) and that the growing in body mass of the preferred prey of the first generation had a major role in driving prey taxa use in the second generation. This showed an important effect of predator-prey size relationships on prey-taxa relationship at individual level and hence on population diet (question 1). Second, we found that the relationship between this strong individual specialization and niche width variation differed when considering prey size or taxa, evidencing two distinct mechanisms of niche variation. For prey size, individual specialization ( $R$ 's $I$ ) remained constant, while the niche width $(T N W)$ increased in the second generation (parallel release); for prey taxa, the second generation showed a wider niche $(D)$, together with a much weaker increase in individual niche width and a decrease in individual prey taxon overlap (IS) (increased among-individual variation) (question 2). To our knowledge, this is the first time that these two mechanisms of niche expansion were observed to occur simultaneously in a natural population of predators. Third, we found that although prey availability certainly accounted for the prey spectrum, $S$. continuus population seemed clearly selective, with the observed taxon-biased selectivity probably most explained by prey distribution among habitat types (bush species preferred over soil species) and then by prey size distribution in the environment (question 3).

We discuss in detail these findings below, highlighting the novel aspects of our study in relation to what is known on prey selection mechanisms in other predatory taxa.

\section{POPULATION-LEVEL SELECTIVITY AND NICHE VARIATION}

The role of prey availability in determining the prey spectrum of $S$. continuus is supported by diet variation on multiple time-scales. Prey records changed between generations and also among years: in 2004 and 2005, Polidori et al. (2009) studied the same population and they found that almost all the prey belonged to the abundant genus Heteracris; in contrast, this genus was much rarer in 2007 and, accordingly, it was only marginally hunted, with most of the prey belonging to the abundant genus Calliptamus. In a single year (2007), the abundance of Tropidopola, for example, increased across generations and, accordingly, wasps conspicuously hunted it late in the season. Variations in the relative abundance of prey types accounted for a temporal variation in diet in other wasp species (e.g. Brockmann 1985; Stubblefield et al. 1993; Grant 2006).

Prey availability, however, only partially explain the S. continuus diet. For example, Acrotylus was almost never hunted in either year the wasp was studied (Polidori et al. 2009; this study), despite its high abundance. Similar patterns of selectivity, where abundant and apparently exploitable taxa are ignored, were also found in other wasp species and were related to size constraints of wasps and/or specialization for particular ecological traits of certain prey types (Karsai, Somogyi \& Hardy 2006; Polidori et al. 2007, 2010). Similarly, the evidence suggests that the selectivity demonstrated by the $S$. continuus population is driven by: (i) strong hunting habitat preference and (ii) functional specialization (because of size constraints). 
First, only grasshoppers living on tall grass, bushes and shrubs were hunted, while genera living on the ground were ignored. Only a controlled experiment would be able to assess whether these particular hunting sites are actively selected, or whether prey selection determines habitat use, although a previous study supports our view. In fact, Asís, Tormos \& Jimenez (1988) have shown that in captivity, S. continuus females accept grasshopper species (including the ground-living Acrotylus), which they normally do not hunt in their environment. Thus, we suggest that habitat types are selected prior to prey species selection. The effect of hunting habitat selection is further suggested by the case of Pyrgomorpha: this genus of prey did not undergo changes in environmental abundance, but it was hunted much more frequently by the second generation, when it was found mostly on bushes. The microhabitat was also shown to account for most prey selectivity in other wasp species: for example, Sceliphron wasps hunt spiders living on two-dimensional webs when terricolous species are more abundant (Polidori et al. 2007) and Cerceris rubida Jurine only hunts phytophagous beetles living in grass fields adjacent to their nesting site (Polidori et al. 2010). Thus, $S$. continuus could probably be considered an 'ecological specialist' (Ferry-Graham, Bolnick \& Wainwright 2002).

Second, predator-prey size relationship accounts for selectivity. Females of the second generation seemed to select the size of prey in accordance with their own size (and thus with their load-lifting capacity), as occurs in other wasp species (Gwynne \& Dodson 1983; Polidori et al. 2005, 2010; Karsai, Somogyi \& Hardy 2006). Furthermore, larger individuals, although preferring larger prey, also hunted small grasshoppers, suggesting that $S$. continuus does not reject small-sized prey, similarly to what is believed to occur in other wasp species (Brockmann 1985; Coelho \& Ladage 1999; Grant 2006). Such relationships appeared in the second generation because of the increase in grasshopper size (which approached the wasps' maximum theoretical load), while they were absent in the first generation because the smaller size of potential prey (well below the wasps' maximum theoretical load) guaranteed their accessibility to most of the wasps. For example, the most used prey in July, Calliptamus, grew in size across generations and an important proportion of individuals (see class 4 in Fig. 3) reached size refuge (Fig. S1a). Size constraints have been shown to account for prey shift in another grasshopper-hunting wasp species (Brockmann 1985). On the other hand, large Tropidopola were hunted by both generations, maybe because of their unique body shape (elongated, slender body with short appendices), which would not prevent its successful transport (see Fig. S1 for comparison with Calliptamus). Thus, $S$. continuus can also be considered a 'functional specialist' (Ferry-Graham, Bolnick \& Wainwright 2002).

Gender and developmental stage of orthopterans did not account for selectivity, as occurs in other wasp species (Stubblefield et al. 1993; Grant 2006; Polidori et al. 2007, 2010).

Hence, prey availability, size and habitat ultimately interacted, leading the $S$. continuus population to expand its niche across generations, both for prey taxa $(D)$ and for prey size $(T N W)$.

\section{INDIVIDUAL SPECIALIZATION AND NICHE VARIATION}

Intraspecific variation in S. continuus was among the strongest ever measured in animals (Bolnick et al. 2003), including the only two other wasp species studied in the past (Araújo \& Gonzaga 2007; Polidori et al. 2010).

Regarding prey size, the strong individual specialization in size was correlated with the remarkable variations in size, shown by female wasps. Size niche expanded across the two generations through a parallel increase in individual niche widths. Parallel release can be predicted by a number of adaptive dynamic and quantitative genetic models, which indicates that individuals should be driven to use the full range of the population's resources (Taper \& Case 1985; Ackermann \& Doebeli 2004). We have shown here that parallel release may also appear at smaller (nonevolutionary) time-scales (e.g. across two generations) as a behavioural response to changes in the prey community.

With respect to prey taxa, niche expanded through increased among-individual variation, according to predications of the NVH. For another wasp species, Araújo \& Gonzaga (2007) showed the same pattern of niche variation for prey taxa across generations. Such a mechanism has been found to be related to a release from interspecific competition (ecological release) (Van Valen 1965; Svanbäck et al. 2008; Bolnick et al. 2010). Alternatively, niche expansion may be achieved through increasing intraspecific competition. This was seen both in experimental (Bolnick 2001; Svanbäck \& Bolnick 2007; Tinker, Bentall \& Estes 2008) and in field studies, which estimate competition with predator density (Svanbäck \& Persson 2004). Limited evidence suggests that this may be possible for $S$. continuus. First, a rough estimate of how many prey are available per wasp $(O D / A D)$ weakly decreased across generations; second, intraspecific preystealing (14 cases) was recorded only in the second generation.

\section{Conclusions}

With the present results, it is possible to build a simplified model of selective predation by $S$. continuus and its consequences on niche variation (Fig. 6). Two females of S. continuus hunt their prey (four items each) almost only on large bushes (sp. 3-4), avoiding nonbush species regardless of abundance (sp.1-2) (Fig. 6a). Wasps segregate their individual diet, partially depending on their functional limits (size constraints). This produces a low overlap of prey taxa and size among individuals (Fig. 6b). Thus, population-level selectivity is the result of complex interactions between individual-level specialization for prey taxa and size. During the season, the increase in preferred prey size and the enlargement of potential prey spectrum lead to niche expansion for both taxa (through minimization of resource use overlap) and size (through parallel release) (Fig. 6c,d). Thus, changes in environmental prey availability and the environmental 


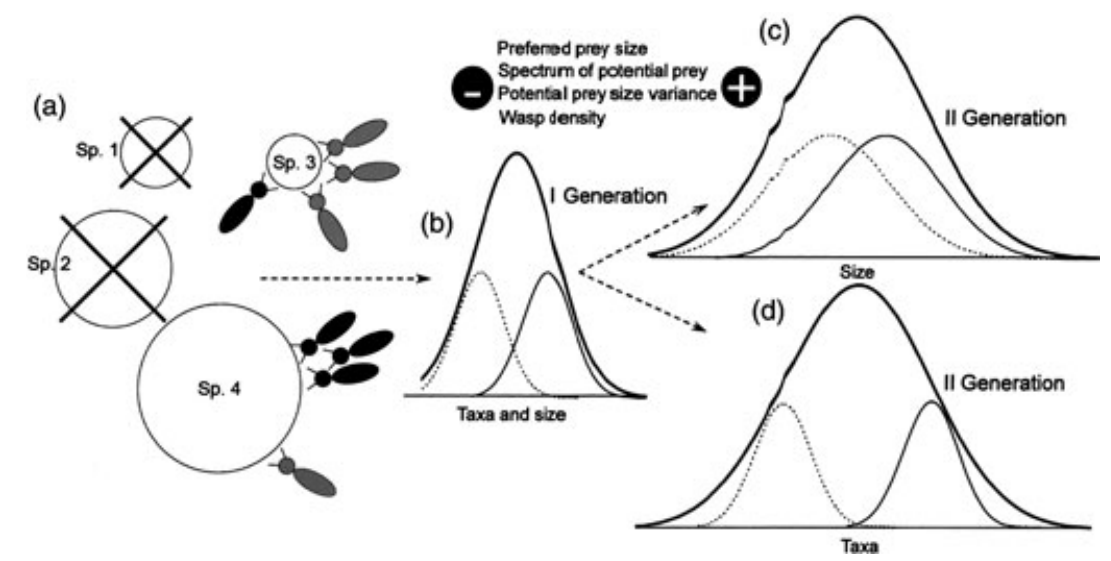

Fig. 6. Simple model of selective predation by $S$. continuus and niche variation. Two females of $S$. continuus hunt their prey (four items each) almost only on large bushes (sp. 3-4), avoiding nonbush species regardless of abundance (sp.1-2), and segregate their individual diet (a) (see also Fig. 1). This produces a low overlap of prey taxa and size among individuals (b). During the season, the increase in preferred prey size, in the potential prey spectrum, in potential prey size variance, and in intraspecific competition leads to a niche expansion for both taxa and size following two different mechanisms. In the case of prey size, the two individuals shifted to using the full set of available resources (d), while for prey taxa each individual continued to use a narrow range of resources but diverged from its conspecific (e).

distribution of prey size interact with individual-based complex behaviour, strongly influencing mechanisms of niche variation. Factors driving niche expansion should be investigated in $S$. continuus in greater depth through experimental set-ups, which could control for possible confounding factors.

\section{Acknowledgements}

Thanks are due to the Town Hall of Valencia and the Generalitat Valenciana for issuing the permits necessary to carry out this work in a Nature Reserve. We are indebted to Marcio Araújo, Dan Bolnick and F. Andrietti, who gave many suggestions for a draft version of the manuscript, and two anonymous referees for the comments which improved the manuscript. J.J. Presa and M.D. García helped with grasshopper identification, and P. Mendiola and G Storino with the field work. Fabiola Barraclough kindly revised the English The research was partially supported by grants from the Spanish Governmen (CGL2006-02568) and Castilla y León government (SA094A09). The experiments comply with current Spanish law.

\section{References}

Ackermann, M. \& Doebeli, M. (2004) Evolution of niche width and adaptive diversification. Evolution, 58, 2599-2612.

Aiken, L.S. \& West, S.G. (1991) Multiple Regression: Testing and Interpreting Interactions. Sage Publications, Newbury Park, CA

Araújo, M.S. \& Gonzaga, M.O. (2007) Individual specialization in the hunting wasp Trypoxylon (Trypargylum) albonigrum (Hymenoptra, Crabronidae). Behavioural Ecology and Sociobiology, 61, 1855-1863.

Asís, J.D., Tormos, J. \& Jimenez, R. (1988) Contribution to the study of the biology of Stizus continuus (Hymenoptera: Sphecidae). Entomological News, 99, 199-206.

Badih, A., Hidalgo, J., Ballesta, M., Ruano, F. \& Tinaut, A. (1997) Distribution and phenology of a community of orthoptera (Insecta) in a dune ecosystem of the southeastern iberian peninsula. Zoologica Baetica, 8, 31-42.

Barclay, R.M.R. \& Brigham, R.M. (1991) Prey detection, dietary niche breadth, and body size in bats: why are aerial insectivorous bats so small? The American Naturalist, 137, 693-703.

Bolnick, D.I. (2001) Intraspecific competition favours niche width expansion in Drosophila melanogaster. Nature, 410, 463-466.

Bolnick, D.I., Yang, L.H., Fordyce, J.A., Davis, J.M. \& Svanbäck, R. (2002) Measuring individual-level resource specialization. Ecology, 83, 2936-2941.

Bolnick, D.I., Svanbäck, R., Fordyce, J.A., Yang, L.H., Davis, J.M., Hulsey, C.D. \& Forister, M.L. (2003) The ecology of individuals: incidence and implications of individual specialization. The American Naturalist, 161, 128

Bolnick, D.I., Svänback, R., Araujo, M.S. \& Persson, L. (2007) Comparative support for the niche variation hypothesis that more generalized populations also are more heterogeneous. Proceedings of the National Academy of Sciences, 104, 10075-10079.

Bolnick, D.I., Ingram, T., Stutz, W.E., Snowberg, L.K., Lau, O.L. \& Paull, J.S. (2010) Ecological release from interspecific competition leads to decoupled changes in population and individual niche width. Proceedings of the Royal Society of London (Series B), 277, 1789-1797.

Brockmann, H.J. (1985) Provisioning behavior of the great golden digger wasp, Sphex ichneumoneus (L.) (Sphecidae). Journal of the Kansas Entomological Society, 58, 631-655.

Clemente, M.E., Garcia, M.D. \& Presa, J.J. (1987) Clave de los generos de saltamontes ibericos (Orthoptera: Caelifera). Segretariado de publicaciones e intercambios centifico, Universidad de Murcia, Espana.

Coelho, J.R. \& Ladage, L.D. (1999) Foraging capacity of the great golden digger wasp Sphex ichneumoneus. Ecological Entomology, 24, 480-483.

Costa, G.C. (2009) Predator size, prey size, and dietary niche breadth relationships in marine predators. Ecology, 90, 2014-2019.

Emmerson, M.C. \& Raffaelli, D.G. (2004) Body size, patterns of interaction strength and the stability of a real food web. Journal of Animal Ecology, 73, 399-409.

Evans, E.W., Roger, E.A. \& Opferman, D.J. (1983) Sampling grasshoppers (Orthoptera: Acrididae) on burned and unburned tallgrass prairie: night trapping vs. sweeping. Environmental Entomology, 62, 1449-1454.

Feinsinger, P. \& Spears, E.E. (1981) A simple measure of niche breadth. Ecology, 62, 27-32.

Ferry-Graham, L.A., Bolnick, D.I. \& Wainwright, P.C. (2002) Using functional morphology to examine the ecology and evolution of specialization. Integrative and Comparative Biology, 42, 265-277.

Futuyma, D.J. \& Moreno, G. (1988) The evolution of ecological specialization. Annual Review of Ecology and Systematics, 19, 207-233.

Grant, P.R. (2006) Opportunistic predation and offspring sex ratios of cicadakiller wasps (Sphecius speciosus Drury). Ecological Entomology, 31, 539-547. Greenleaf, S.S., Williams, N.M., Winfree, R. \& Kremen, C. (2007) Bee foraging ranges and their relationship with body size. Oecologia, 153, 589-596.

Gwynne, D.T. \& Dodson, G.N. (1983) Nonrandom provisioning by the digger wasp, Palmodes laeviventris (Hymenoptera: Sphecidae). Annals of The Entomological Society of America, 76, 434-436.

Hurlbert, S.H. (1978) The measurement of niche overlap and some relatives. Ecology, 59, 67-77.

Huseynov, E.F., Jackson, R.R. \& Cross, F.R. (2008) The meaning of predator specialization as illustrated by Aelurillus m-nigrum, an ant-eating jumping spider (Araneae: Salticidae) from Azerbaijan. Behavioral Processes, 77, 389-399.

Irschick, D., Dyer, L. \& Sherry, T.W. (2005) Phylogenetic methodologies for studying specialization. Oikos, 110, 404-408. 
Johnson, D.H. (1980) The comparison of usage and availability measurements for evaluating resource preference. Ecology, 61, 65-71.

Karsai, I., Somogyi, K. \& Hardy, I.C.W. (2006) Body size, host choice and sex allocation in a spider-hunting pompilid wasp. Biological Journal of the Linnean Society, 87, 285-296.

Levins, R. (1968) Evolution in Changing Environments: Some Theoretical Explorations. Princeton University Press, Princeton, NJ, USA.

Liao, H., Pierce, C.L. \& Larscheid, J.G. (2001) Empirical assessment of indices of prey importance in the diets of predacious fish. Transactions of the American Fisheries Society, 130, 583-591.

Marden, J.H. (1987) Maximum lift production during takeoff in flying animals. Journal of Experimental Biology, 130, 235-258.

O’Neill, K.M. (2001) Solitary Wasps: Behaviour and Natural History. Cornel University Press, Ithaca, NY, USA.

Polidori, C., Boesi, R., Isola, F. \& Andrietti, F. (2005) Provisioning patterns and choice of prey in the digger wasp Cerceris arenaria (Hymenoptera: Crabronidae): the role of prey size. European Journal of Entomology, 102, 801804.

Polidori, C., Federici, M., Pesarini, M. \& Andrietti, F. (2007) Factors affecting spider prey selection by Sceliphron mud-dauber wasps (Hymenoptera: Sphecidae) in northern Italy. Animal Biology, 57, 11-28.

Polidori, C., Mendiola, P., Asís, J.D., Tormos, J., Selfa, J. \& Andrietti, J. (2008) Inter-attraction influences nest establishment in the digger wasp Stizus continuus (Hymenoptera: Crabronidae). Animal Behaviour, 75, 16511661.

Polidori, C., Mendiola, P., Asís, J.D., Tormos, J., Garcia, M.D. \& Selfa, J. (2009) Predatory habits of the grasshopper-hunting wasp Stizus continuus (Hymenoptera: Crabronidae): diet preference, predator-prey size relationships and foraging capacity. Journal of Natural History, 43, 2985-3000.

Polidori, C., Gobbi, M., Chatenaud, L., Santoro, D., Montani, O. \& Andrietti, F. (2010) Taxon-biased diet preference in the 'generalist' beetle-hunting wasp Cerceris rubida provides insights on the evolution of prey specialization in apoid wasps. Biological Journal of the Linnean Society, 99, 544-558.

Roughgarden, J. (1974) Niche width: biogeographic patterns among Anolis lizard populations. The American Naturalist, 108, 429-442.

Stubblefield, J.W., Seger, J., Wenzel, W. \& Heisler, M.M. (1993) Temporal, spatial, sex-ratio and body-size heterogeneity of prey species taken by the beewolf Philanthus sanbornii (Hymenoptera: Sphecidae). Philosophical Transactions of the Royal Society of London (Series B), 339, 397-423.

Svanbäck, R. \& Bolnick, D.I. (2007) Intraspecific competition drives increased resource use diversity within a natural population. Proceedings of the Royal Society of London (Series B), 274, 839-844.

Svanbäck, R. \& Persson, L. (2004) Individual diet specialization, niche width and population dynamics: implications for trophic polymorphism. Journal of Animal Ecology, 73, 973-982.

Svanbäck, R., Eklöv, P., Fransson, R. \& Holmgren, K. (2008) Intra-specific competition drives multiple species trophic polymorphism in fish communities. Oikos, 117, 114-124.

Taper, M.L. \& Case, T.J. (1985) Quantitative genetic models for the coevolution of character displacement. Ecology, 66, 355-371.

Tinker, M.T., Bentall, G. \& Estes, J.A. (2008) Food limitation leads to behavioral diversification and dietary specialization in sea otters. Proceedings of the National Academy of Sciences, 2, 560-565.

Van Valen, L. (1965) Morphological variation and width of ecological niche. The American Naturalist, 99, 377-390.

Received 28 May 2010; accepted 9 May 2011

Handling Editor: Frank van Veen

\section{Supporting Information}

Additional Supporting Information may be found in the online version of this article.

Table S1. Indices used in the analysis.

Table S2. Number of individuals of orthopterans collected (and identified at least at the generic level) from the environment (E) and among wasp prey $(\mathrm{P})$ during the activity of the two generations (first generation: I; second generation: II), and statistical differences between frequencies (only if sample size adequate). In brackets the collected species for each genus are shown.

Table S3. Number of individuals of grasshoppers of the seven most hunted genera collected in the two different habitats considered, and statistical differences between frequencies (only if sample size adequate).

Table S4. Mean weight \pm SD (mg) of orthopterans collected from the environment $(\mathrm{E})$ and among wasp prey $(\mathrm{P})$, and the theoretical maximum lift (Max lift) of wasps which hunted for each genus, during the activity of the two generations (first generation: I; second generation: II).

Table S5. Number of individuals of the three most abundant orthopteran genera per size class collected from the environment (E) and among wasp prey $(\mathrm{P})$ during the activity of the two generations (first generation: I; second generation: II), and statistical differences between frequencies.

Fig. S1. Pictures showing the very different body shapes of two abundantly grasshopper genera. (a) Tropidopola, (b) Calliptamus (lateral and dorsal view).

As a service to our authors and readers, this journal provides supporting information supplied by the authors. Such materials may be reorganised for online delivery, but are not copy-edited or typeset. Technical support issues arising from supporting information (other than missing files) should be addressed to the authors. 